\title{
Erratum regarding missing Declaration of Competing Interest statements in previously published articles
}

Declaration of Competing Interest statements were not included in published version of the following articles that appeared in previous issues of Clinical Epidemiology and Global Health. Hence, the authors of the below articles were contacted after publication to request a Declaration of Interest statement:

1 Perception about migration among Oraon Tribes in India" [Clinical Epidemiology and Global Health, 2020; 8 : 616-622] DOI: https://do i.org/10.1016/j.cegh.2019.12.013

2 "Burden of illness of dog-mediated rabies in India: a systematic review" [Clinical Epidemiology and Global Health, 2021; 12 : 100804] DOI: https://doi.org/10.1016/j.cegh.2021.100804

3 "Prevalence and detecting spatial clustering of anaemia among children 6-59 months in the districts of India" [Clinical Epidemiology and Global Health, 2021; 12 : 100845] DOI: https://doi. org/10.1016/j.cegh.2021.100845
4 Informing Primi and Elderly Pregnant Women about Iron Sucrose Administration for Moderate Anemia Can Improve Treatment Compliance in Public Health Facilities, Kancheepuram health district, Tamil Nadu, India, 2017: A cross-sectional study" [Clinical Epidemiology and Global Health, 2021; 10 : 100681] DOI: htt ps://doi.org/10.1016/j.cegh.2020.100681

5 "Impact of COVID-19 pandemic on mental health, risk perception and coping strategies among health care workers in Albania - evidence that needs attention" [Clinical Epidemiology and Global Health, 2021; 12: 100824] DOI: https://doi.org/10.1016/j.cegh.20 21.100824

6 Impact of clinical pharmacist on medication adherence among psoriasis patients: a randomized controlled study" [Clinical Epidemiology and Global Health, 2021; 10: 100687] DOI: https://doi.org/10 .1016/j.cegh.2020.100687.

DOIs of original article: https://doi.org/10.1016/j.cegh.2019.12.013, https://doi.org/10.1016/j.cegh.2021.100804, https://doi.org/10.1016/j.cegh.2021. 100845, https://doi.org/10.1016/j.cegh.2020.100681, https://doi.org/10.1016/j.cegh.2021.100824, https://doi.org/10.1016/j.cegh.2020.100687. 